\title{
X-ray, K-Edge Measurement of Uranium Concentration in Reactor Fuel Plates
}

\author{
Project CH-15C2-51

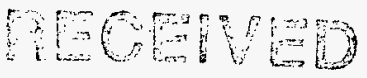 \\ Ap? 22 1989 \\ T. Jensen, T. Aljundi, C. Whitmore, H. Zhong, and Jiay \\ Center for NDE and Ames Laboratory
}

Iowa State University

Ames, IA 50011

DTIC QOALTTY INSPECTED 2

\begin{abstract}
Under the Characterization, Monitoring, and Sensor Technology Crosscutting Program, we have designed and built a K-edge heavy-metal detector that measures the level of heavy-metal content inside closed containers in a nondestructive, non-invasive way. We have applied this technique to measurement of the amount of uranium in stacks of reactor fuel plates containing nuclear materials of different enrichments and alloys. We have obtained good agreement with expected uranium concentrations ranging from $60 \mathrm{mg} / \mathrm{cm}^{2}$ to $3000 \mathrm{mg} / \mathrm{cm}^{2}$, and have demonstrated that the instrument can operate in a high radiation field $(>200 \mathrm{mR} / \mathrm{hr})$.
\end{abstract}

November 26, 1997
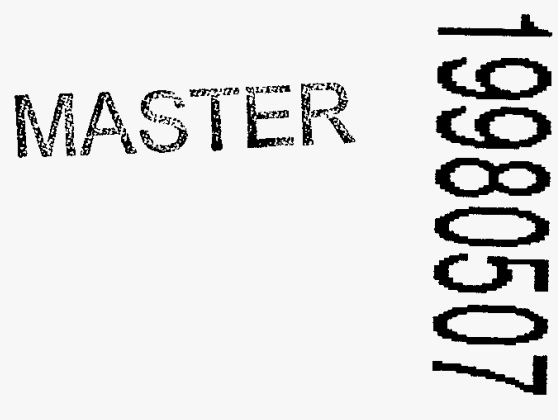

DISTPISUTION OF THIS DOCUMINT IS UALIMTTED

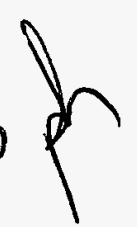




\section{DISCLAIMER}

This report was prepared as an account of work sponsored by an ageney of the United States Government. Neither the United States Government nor any agency thereof, nor any of their employeen, makes any warranty, express or implied, or axsumes any legal liability or responsibility for the aceuracy, completeness, or usefulness of any information, apparatus, product, of process disclosed, or represents that its use would not infringe privately owned rights. Reference herein to any specific commercial producr, process, or service by trade name, trademart, manufacturer, of otherwise does not necessarily constitute or imply its endorsement, recommendation, or favoring by the United States Governmeat or any ageacy thereof. The views and opinions of authors expressed herein do not necessarily state or reflect those of the United States Government or any agency thereof. 


\section{Introduction}

At Idaho National Engineering and Environmental Laboratory (INEEL) there are many diverse types of spent nuclear fuel stored, including production fuels, experimental fuels, research reactor fuels, and commercial fuels[1]. Records for some of the older inventory are not complete, leading to compliance problems with NRC, DOT, and IAEA requirements for qualifying the spent fuel for repository acceptance. In particular, the fissile material content, source term, and burnup of the spent fuel must be known.

Presently, nondestructive assay (NDA) methods based on gamma and neutron emissions are used to characterize spent fuel. However, these measurements require corrections based on the geometry and material properties, and incomplete knowledge leads to large uncertainties in the results. This is further complicated by the fact that some of these materials have corroded over time.

There is a similar need for spent fuel characterization at the Westinghouse Savannah River Company, where spent fuel from foreign reactors is received for storage[2]. The enrichment and burnup of this fuel must be confirmed.

$\mathrm{K}$-edge densitometry is a technique that could be used to improve the characterization of spent nuclear fuel. In previous work[3-6] we have evaluated and enhanced this method to identify and quantify the presence of heavy elements in a mixture. The technique is non-invasive, nondestructive, and most suitable for quantification of heavy metals present inside closed containers.

The absorption of photons is governed by the binding energies of atomic electrons. Each element has a unique distribution of atomic electrons, with the K-shell having the highest binding energy. When a photon has just enough energy to liberate one of the atomic electrons there will be a sudden increase in the rate of absorption. In K-edge densitometry analysis, a Xray beam is made to pass through a sample to a collimated energy-sensitive X-ray detector. At an energy corresponding to an absorption edge for an element, there will be a sudden change in the transmission rate, resulting in a step in the transmitted X-ray spectrum, as indicated in Fig. 1 for a gold sample placed in the beam. The abrupt change in the transmitted intensity at the K-edge energy identifies the element. The amount of that element present can be calculated based on the size of the edge according to the equation,

$$
X=\frac{\ln \left[\frac{I\left(E_{-}\right)}{I\left(E_{+}\right)}\right]}{\mu\left(E_{+}\right)-\mu\left(E_{-}\right)},
$$

where $\mathrm{I}\left(\mathrm{E}_{+}\right)$and $\mathrm{I}\left(\mathrm{E}_{-}\right)$are the measured intensities on either side of the $\mathrm{K}$-edge, as indicated in Fig. 2, and $\mu\left(E_{+}\right)$and $\mu\left(E_{-}\right)$are the corresponding absorption coefficients. To first order the accuracy will be determined by the statistics of the intensity measurements. It is generally possible to achieve a precision of $5-10 \%$ within a few minutes measurement time. For relatively thick amounts of material it is necessary to modify Eq. 1 to account for background in the data. Further details on K-edge densitometry analysis can be found in Refs. 3, 7, and 8. 
In this report we describe the application of the K-edge technique to measurement of the total uranium content in reactor fuel plates. We give a brief description of the prototype K-edge system, and describe a series of measurements made on fuel plates from the Iowa State University UTR-10 reactor. We conclude with an analysis of the potential for applying the technique to characterization of spent nuclear fuel.

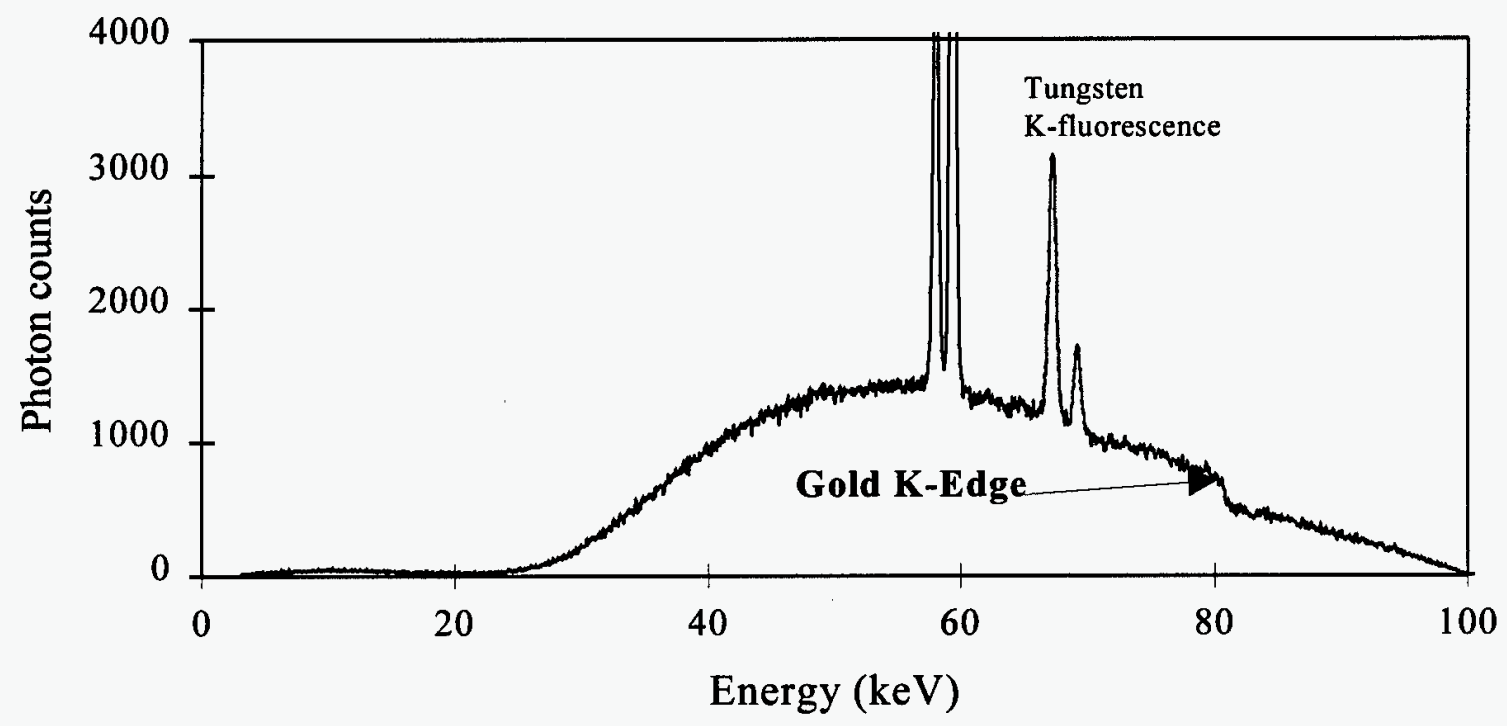

Figure 1. X-ray transmission spectrum through a gold foil.

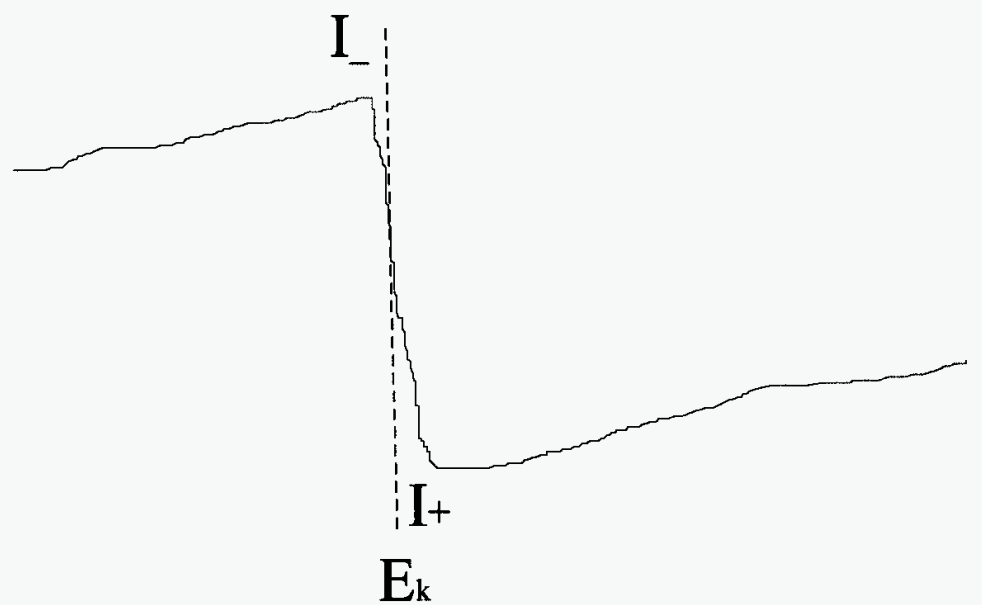

Figure 2. X-ray transmission spectrum in the vicinity of the K-edge of an element. 


\section{Prototype Mobile K-Edge Inspection System}

To handle a variety of different situations, we have assembled a flexible prototype inspection system consisting of four major components: a X-ray generator, a sample holder/positioner, a detection system consisting of the X-ray detector and an imaging system, and a data acquisition system consisting of an industrial personal computer running a Windows-based user interface software to control the device. Figure 3 shows a schematic drawing of the prototype K-edge system.

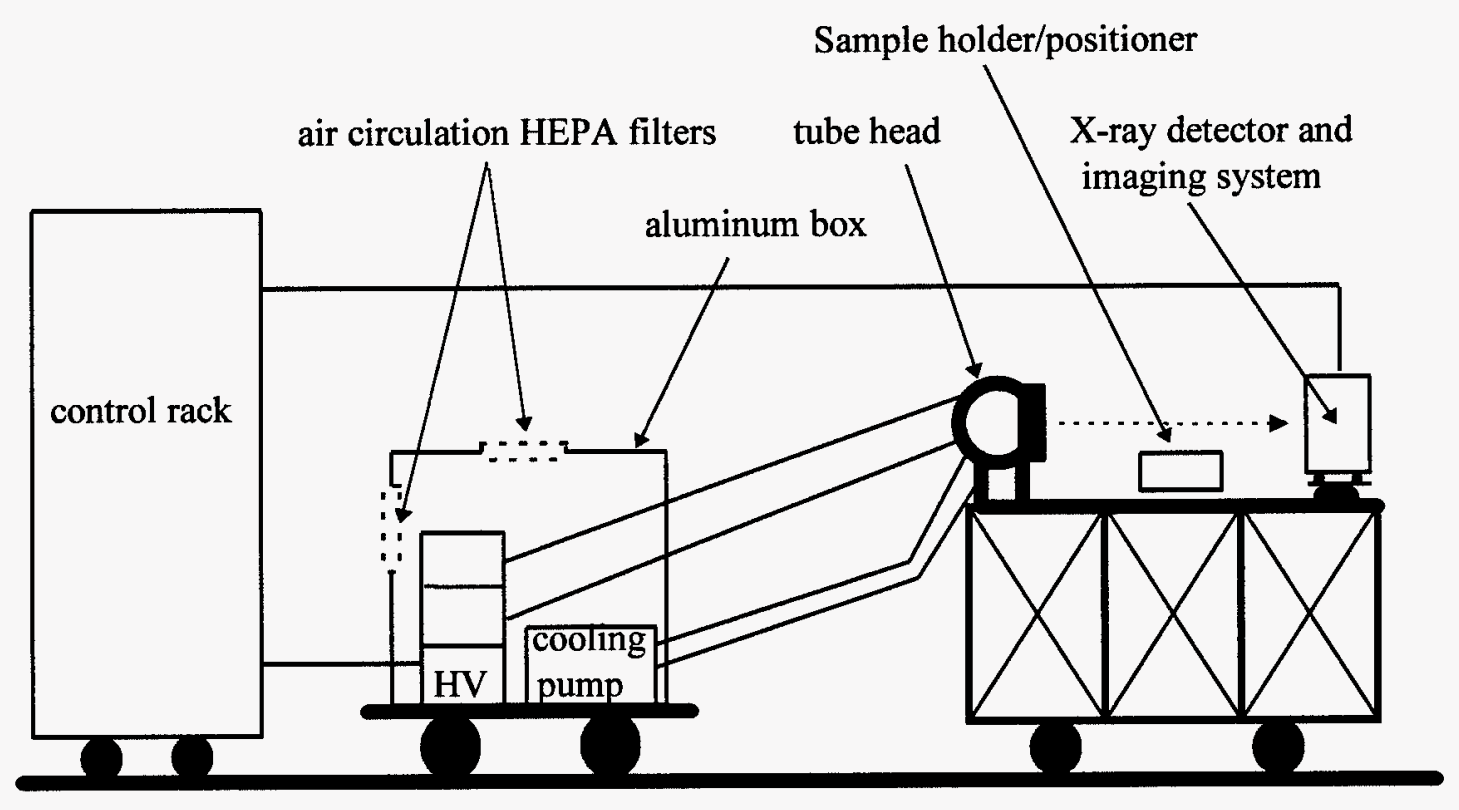

Figure 3. Schematic drawing of the prototype K-edge heavy metal detector.

The X-ray tube has a maximum voltage of $320 \mathrm{kV}$ and a maximum tube load of $4.2 \mathrm{~kW}$. The tube head and detector system are mounted on a support frame that can be easily dismounted and reassembled to suit the configuration of the inspected object. The high voltage supply and the cooling pump are carried on a cart enclosed with an aluminum box with HEPA filters for protection from contamination by radioactive materials. The $\mathrm{X}$-ray tube, detectors, and cables can be wrapped in plastic to protect them from contamination.

The detection system consists of an energy-sensitive X-ray detector and a real-time X-ray imaging system. The X-ray detector is a high purity germanium (HPGe) detector which is cooled using a 1.2 liter liquid nitrogen dewar that can be operated in any orientation. The HPGe detector and imaging system set next to each other on a platform that can be moved to center one system or the other on the X-ray beam. Because heavy metals are strong X-ray absorbers, they will generally produce good contrast in X-ray images. The real-time $\mathrm{X}$-ray image provides a quick qualitative indication of heavy metal location. The HPGe detector can then be positioned to obtain a precise measure of contamination.

Operation of the $\mathrm{K}$-edge system is controlled through a PC located in the system control rack. This rack can be positioned 50-100 feet from the X-ray tube, minimizing the risk of X-ray exposure for the operator. The driving software is a Microsoft Windows based program which 
provides control over the $\mathrm{X}$-ray imaging and data acquisition. Results on heavy metal content are provided in real time to the operator. Further details on the K-edge system can be found in Reference 3.

\section{Reactor Fuel Plate Measurements}

To demonstrate the viability of using the K-edge technique in characterizing spent nuclear fuel, we set up the prototype K-edge system in the Nuclear Engineering Laboratory on the campus of Iowa State University, where we performed a series of measurements on fuel plates from the UTR-10 University Teaching and Research reactor. This reactor can be configured to operate with either high-enrichment uranium (HEU) or low-enrichment uranium (LEU) fuel. Both types of fuel plates have the same transverse dimensions ( 3.0 in. $x 26.0$ in.), but are of different thickness. Figure 4 shows a picture of a stack of 24 dummy plates of LEU fuel as they would be assembled for insertion into the reactor. Each LEU fuel plate is composed of $\mathrm{U}_{3} \mathrm{Si}_{2}$ in an aluminum matrix 0.020 inch thick clad on both sides with 0.015 inch aluminum. The enrichment is $19.75 \%$, and from the manufacturer's specifications the nominal concentration of uranium is calculated to be $176.5 \mathrm{mg} / \mathrm{cm}^{2}$. The HEU plates contain a uranium-aluminum alloy 0.040 inch thick clad with 0.015 inch thick aluminum. The enrichment is $93 \%$, implying a nominal uranium concentration of $58.7 \mathrm{mg} / \mathrm{cm}^{2}$. Most of the plates that we used had not been irradiated, which simplified our measurement procedures. To demonstrate that background radiation from spent fuel would not bias the K-edge measurements, we did make a few tests using irradiated fuel plates.

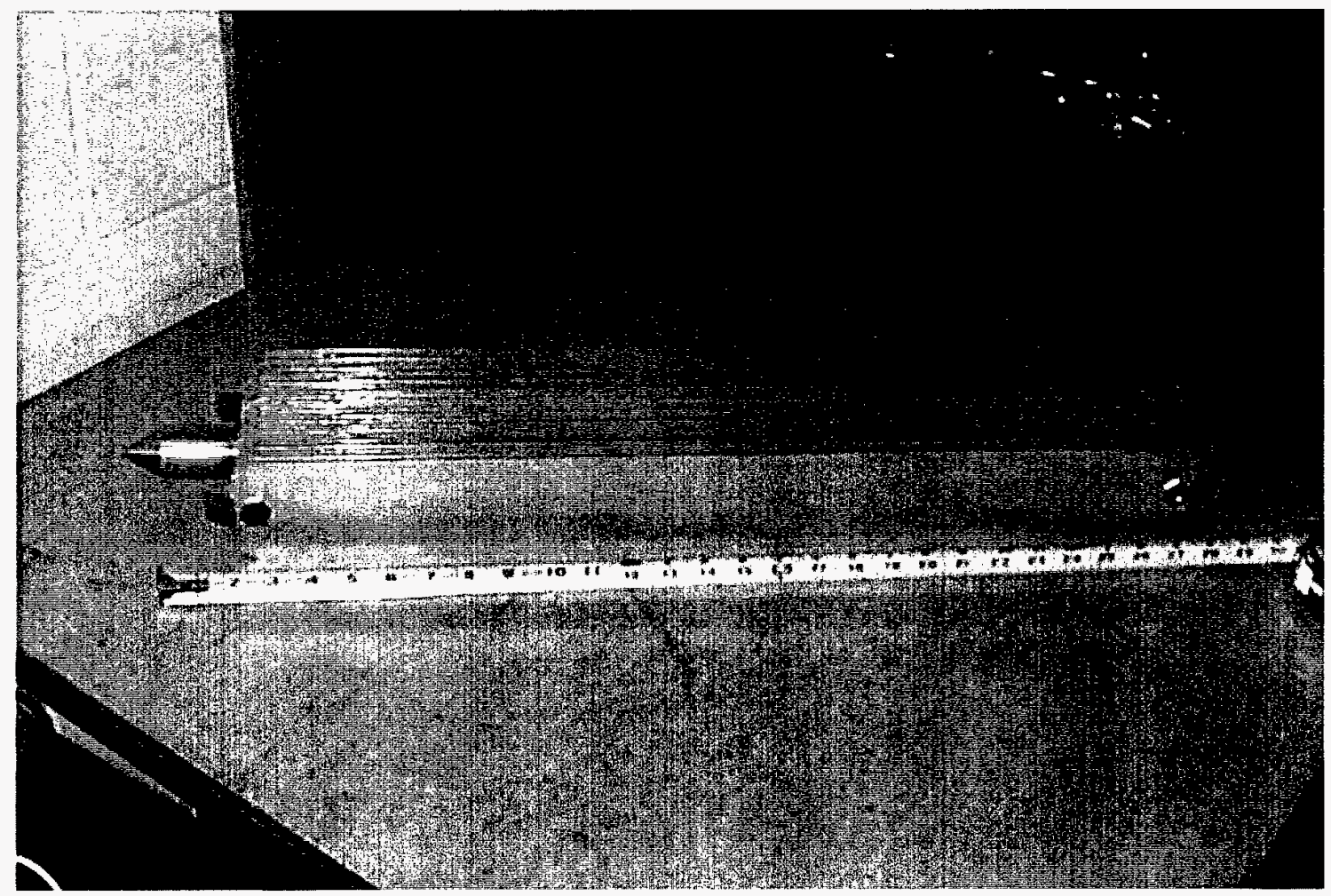

Figure 4. Assembly of 24 dummy LEU fuel plates. 
A picture of the K-edge system as set up in the Nuclear Engineering Lab is shown in Fig. 5. The X-ray tube and detector are located on the other side of the reactor core and are surrounded by some additional portable shielding to minimize local radiation fields. The operator is shown at the control console located a safe distance from the $\mathrm{X}$-ray source.

Stacks of differing numbers of fuel plates were placed on the sample positioner for inspection. The stack could be moved across the X-ray beam by remote control to obtain an image or a K-edge measurement at desired locations. Figure 6 shows images near the ends of the two types of plates, and Fig. 7 shows an image of a step wedge formed by stacking six LEU plates together. (Note that a laser printer image does not have the contrast that a monitor image does.)

It can be seen from Fig. 6 that the ends of the fuel plates are somewhat irregular. This could introduce some error into the calculation of the nominal uranium concentration. It is also possible that the uranium is not distributed uniformly throughout the plate. To test this we have scanned along several of the plates measuring the concentration at different points. The results of a coarse scan along a HEU plate are plotted in Fig. 8. The average of these measurements is 57.2 $\mathrm{mg} / \mathrm{cm}^{2}$ which is in good agreement with the predicted value $\left(58.7 \mathrm{mg} / \mathrm{cm}^{2}\right)$. A fine scan around the central region of the plate yielded the results plotted in Fig. 9, with an average concentration of $54.3 \mathrm{mg} / \mathrm{cm}^{2}$. Measurements taken near the end of a LEU plate are plotted in Fig. 10.

Excluding the first four points at the edge of the plate, the average concentration is 174.8 $\mathrm{mg} / \mathrm{cm}^{2}$, again comparing very well with the predicted value $\left(176.5 \mathrm{mg} / \mathrm{cm}^{2}\right)$. From these scans, as well as others, we conclude that the uranium is uniformly distributed in the fuel plates to within $10 \%$ of the nominal concentration.

In performing the K-edge measurements we placed varying numbers of fuel plates in the $\mathrm{X}$-ray beam and then placed differing amounts of material around the plates ( 1 inch aluminum, $1 / 2$ inch aluminum plus 4 inches water, $1 / 4$ inch steel, or $1 / 2$ inch steel). For each arrangement we made five repeat measurements, collecting data for 2-3 minutes each time. The average of these five measurements is plotted in Fig. 11 as a function of the number of LEU plates being inspected. The error bars on these points correspond to the rms deviations for the five measurements. A similar set of measurements acquired for HEU plates is presented in Fig. 12.

The K-edge measurements show good agreement with predictions for uranium concentrations ranging from $60 \mathrm{mg} / \mathrm{cm}^{2}$ to $3000 \mathrm{mg} / \mathrm{cm}^{2}$ under a variety of matrix conditions. Least squares fits to the data yield average uranium concentrations of $182.4 \mathrm{mg} / \mathrm{cm}^{2}$, and 61.4 $\mathrm{mg} / \mathrm{cm}^{2}$, for a single LEU, and HEU plate, respectively. These are within $5 \%$ of the calculated nominal concentrations.

We also had access to some HEU plates which had been irradiated. K-edge measurements were made on a single plate and on a stack of six plates as indicated in Fig. 12. The results are seen to be in good agreement with the measurements on the unirradiated plates. The radiation field in the vicinity of the detector $(\sim 10 \mathrm{~cm}$ from the plates) was $20 \mathrm{mR} / \mathrm{hr}$ for the single plate and $200 \mathrm{mR} / \mathrm{hr}$ for the six-plate stack. It was possible to shield the detector so that this background radiation did not affect the K-edge measurements. 


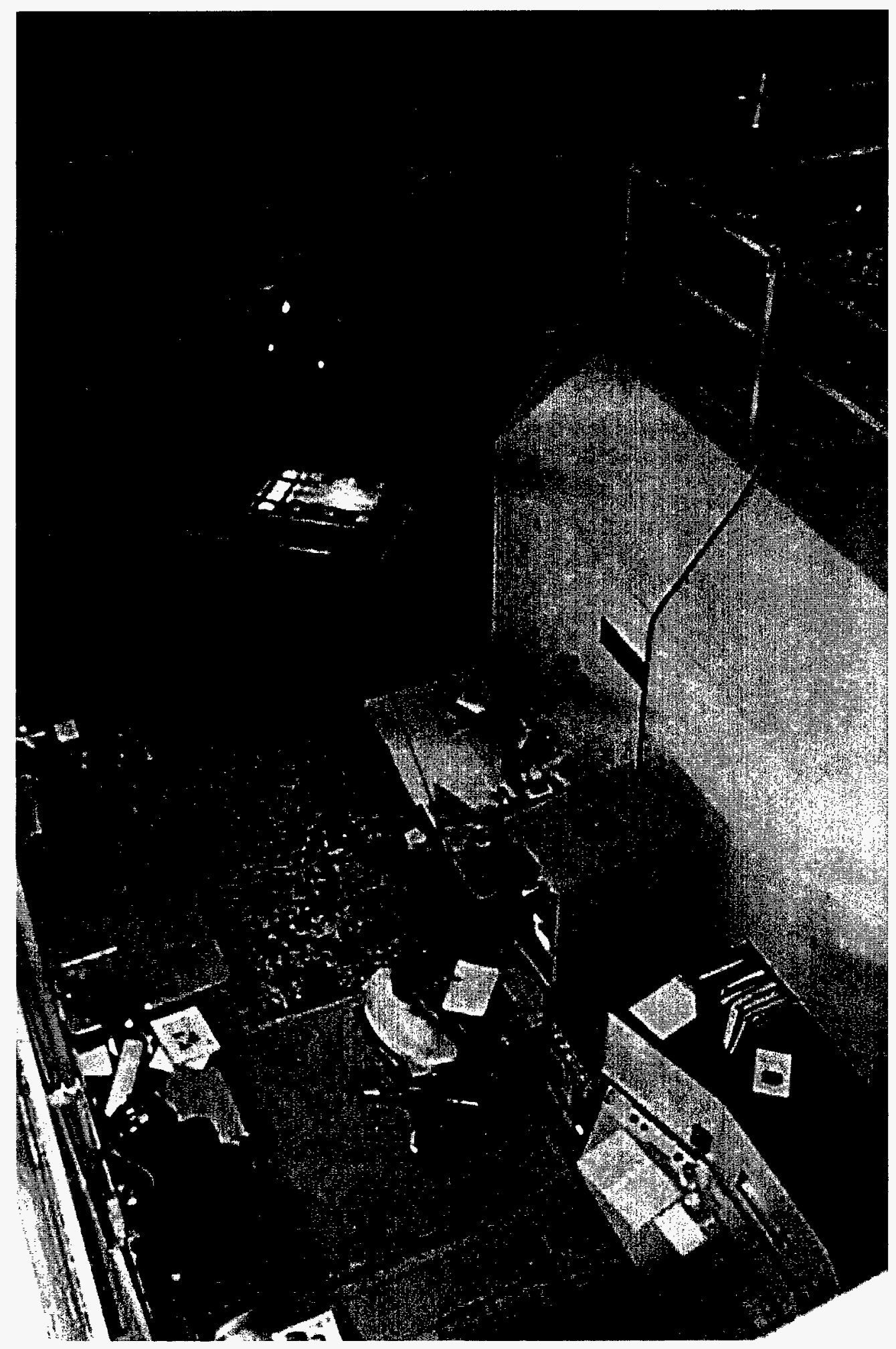

Figure 5. Setup of K-edge system at the ISU UTR-10 Reactor. The operator is seated at the Kedge system console and the HV supply cart can be seen in the upper left of the picture. The Xray tube and detector are located on the other side of the reactor core. 


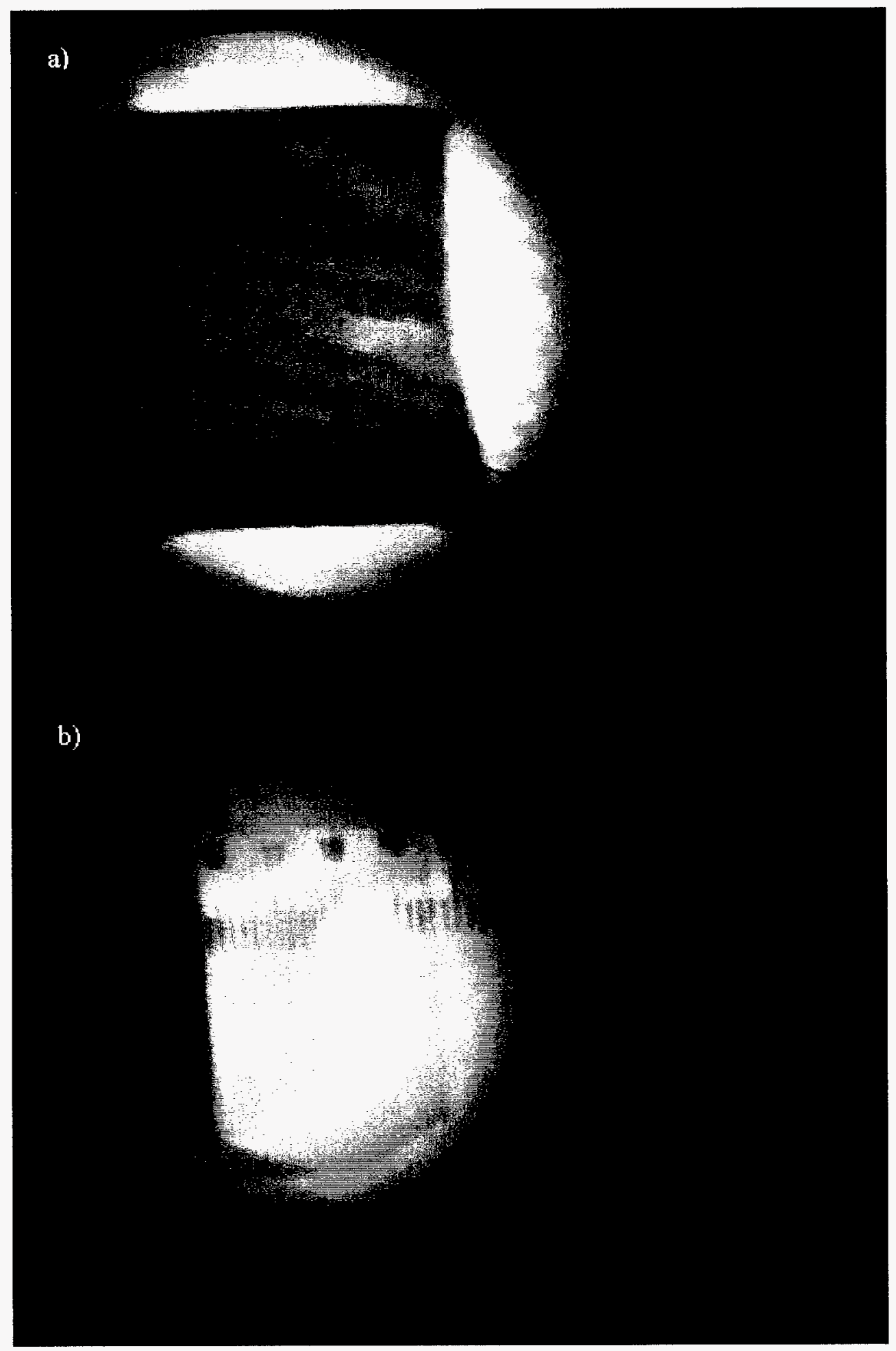

Figure 6. Real-time X-ray image near the end of a) a LEU fuel plate, and b) a HEU fuel plate. The active area of the X-ray imager is about four inches in diameter. In b) a ruler with $2 \mathrm{~mm}$ increments is placed on the fuel plate to show the distance from the edge of the uranium to the mounting hole. 


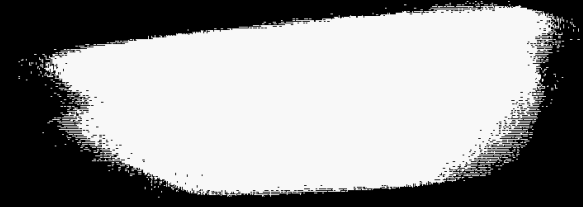

Figure 7. Real-time X-ray image of a step wedge formed by stacking fuel plates together.

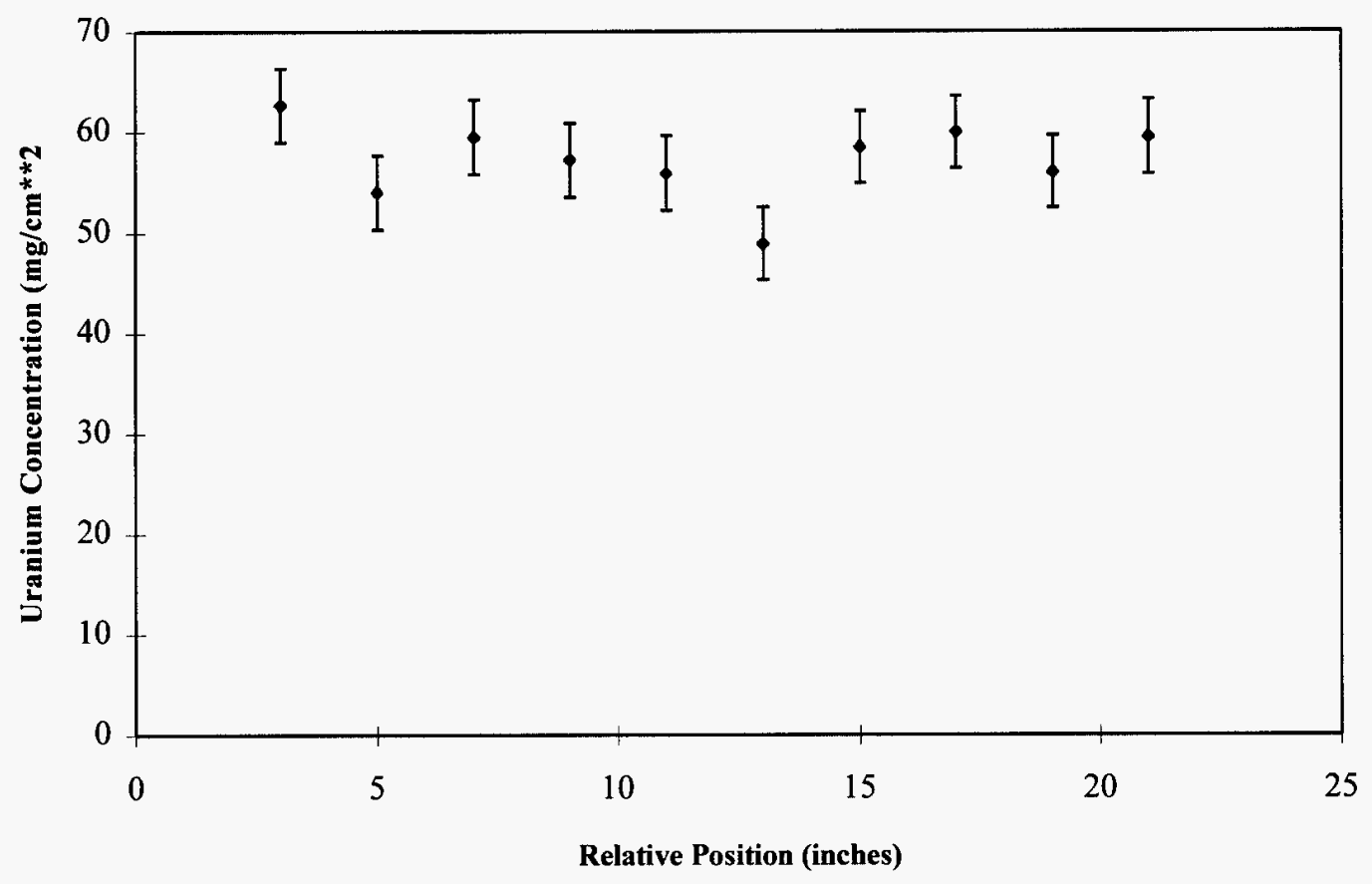

Figure 8. K-edge measurements as a function of position along a HEU fuel plate. Data were accumulated for approximately six minutes at each point. 


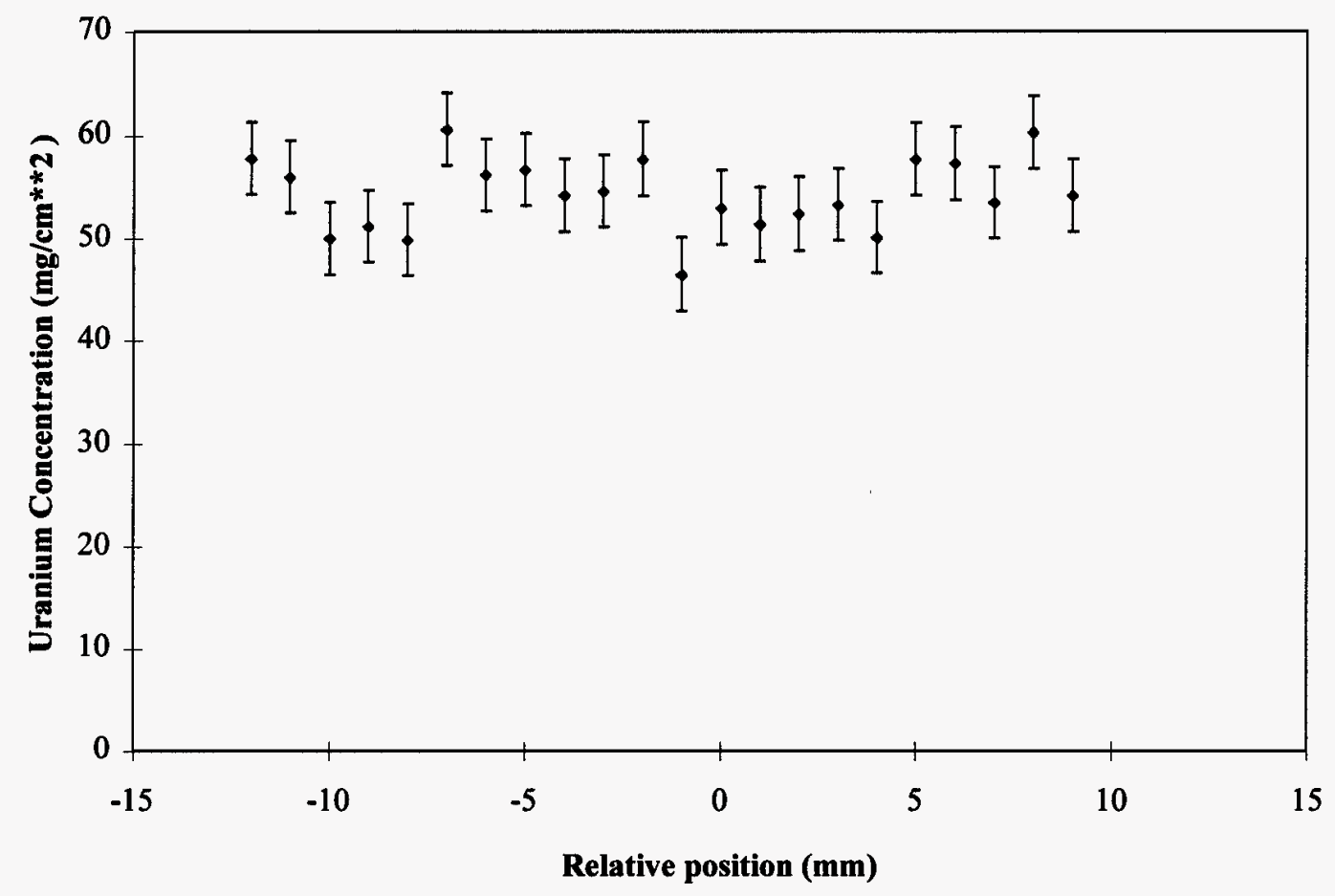

Figure 9. K-edge measurements as a function of position in the central region of a HEU fuel plate.

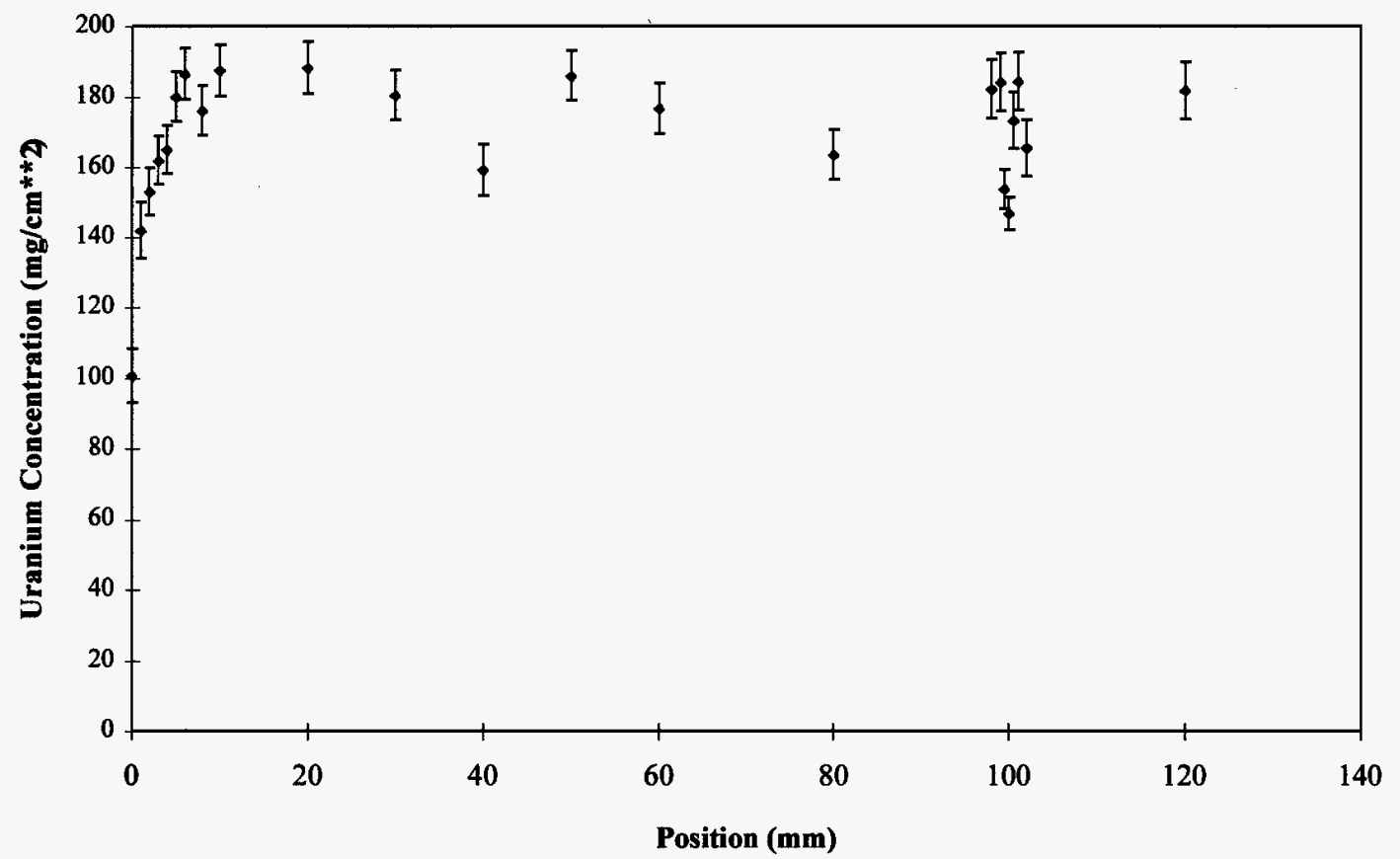

Figure 10. K-edge measurements as a function of position along a LEU fuel plate. 

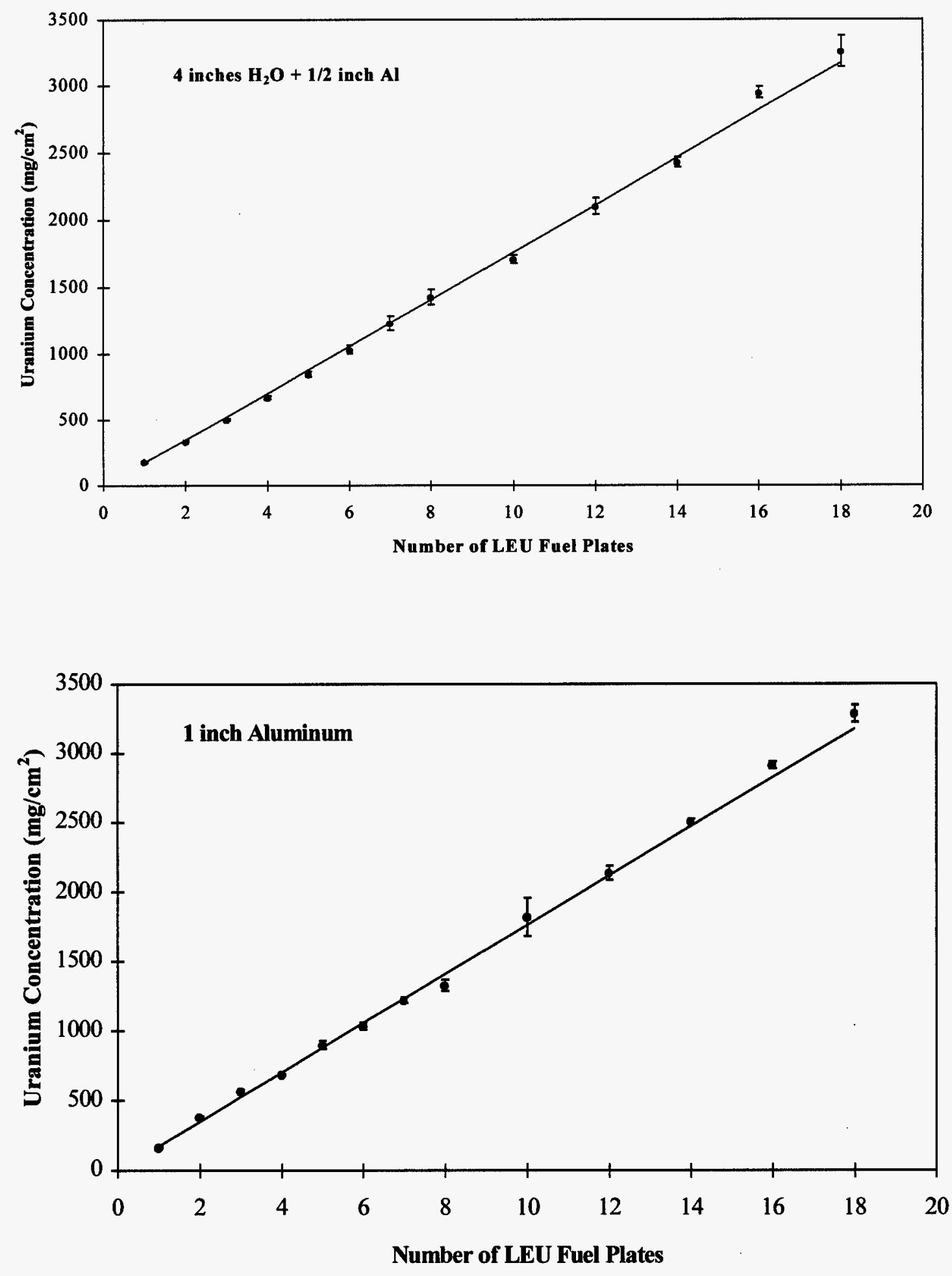

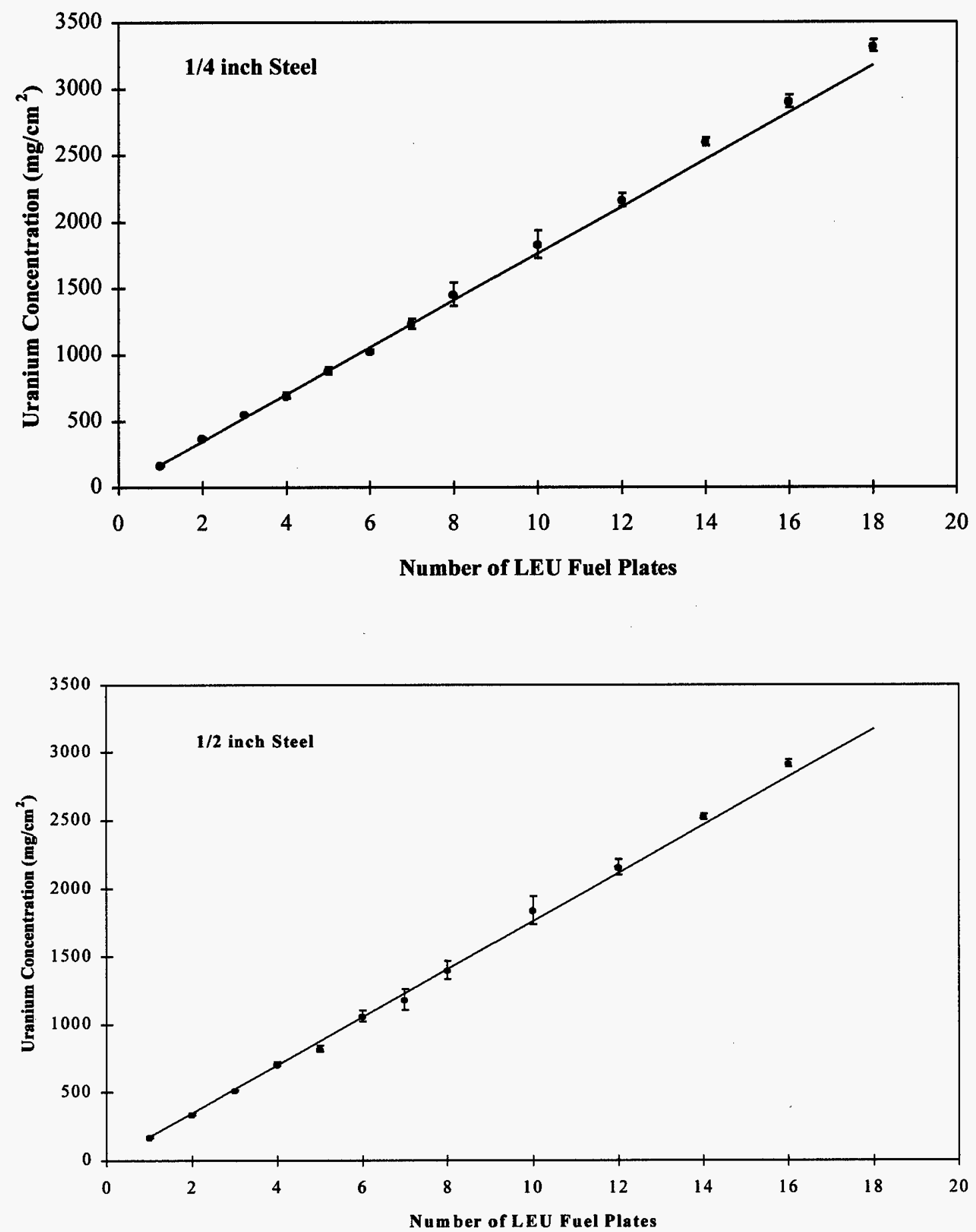

Figure 11. K-edge measurement of uranium concentration as a function of the number of LEU fuel plates in a stack for different matrix materials. The solid line indicates the expected concentration based on the manufacturer's specifications. 

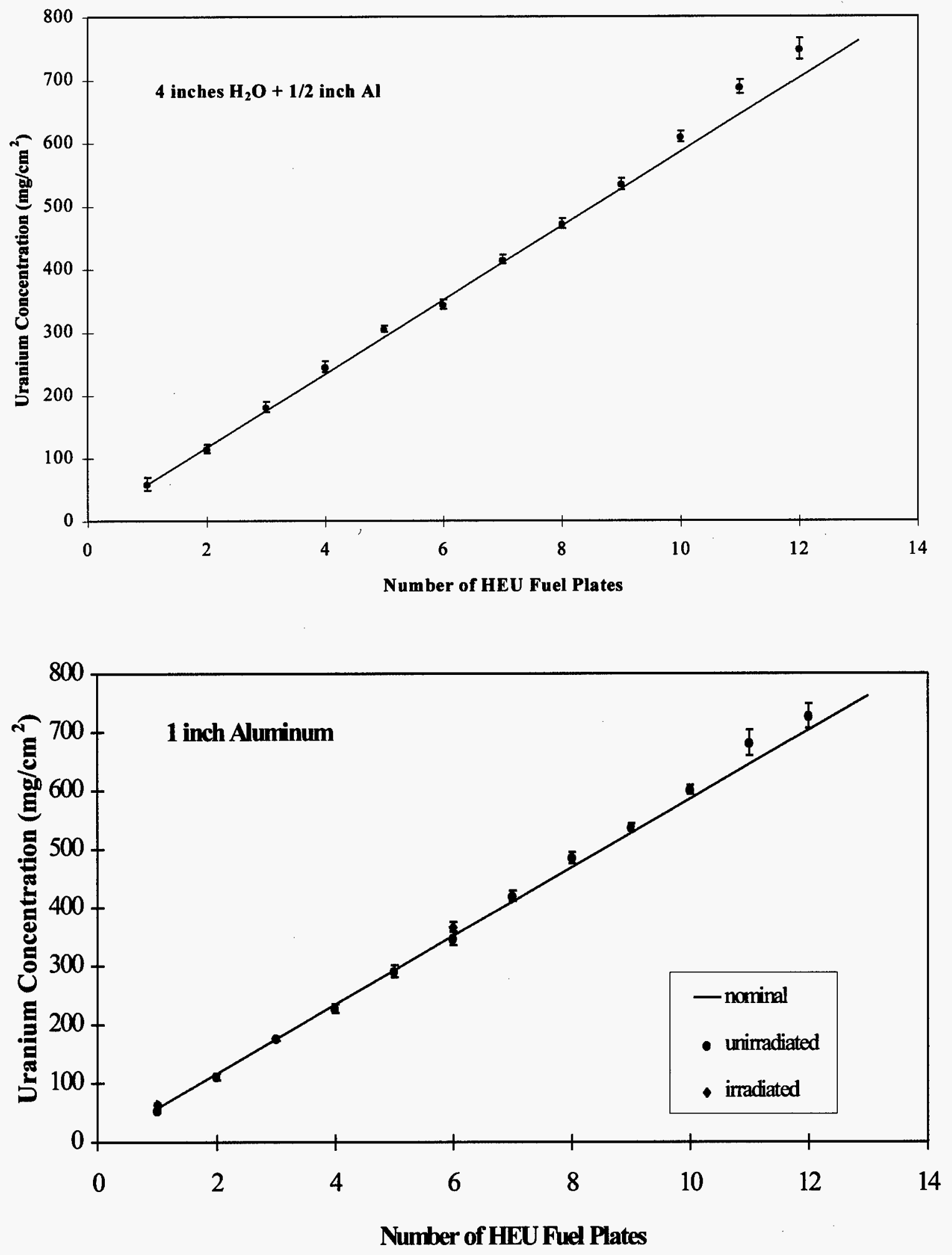

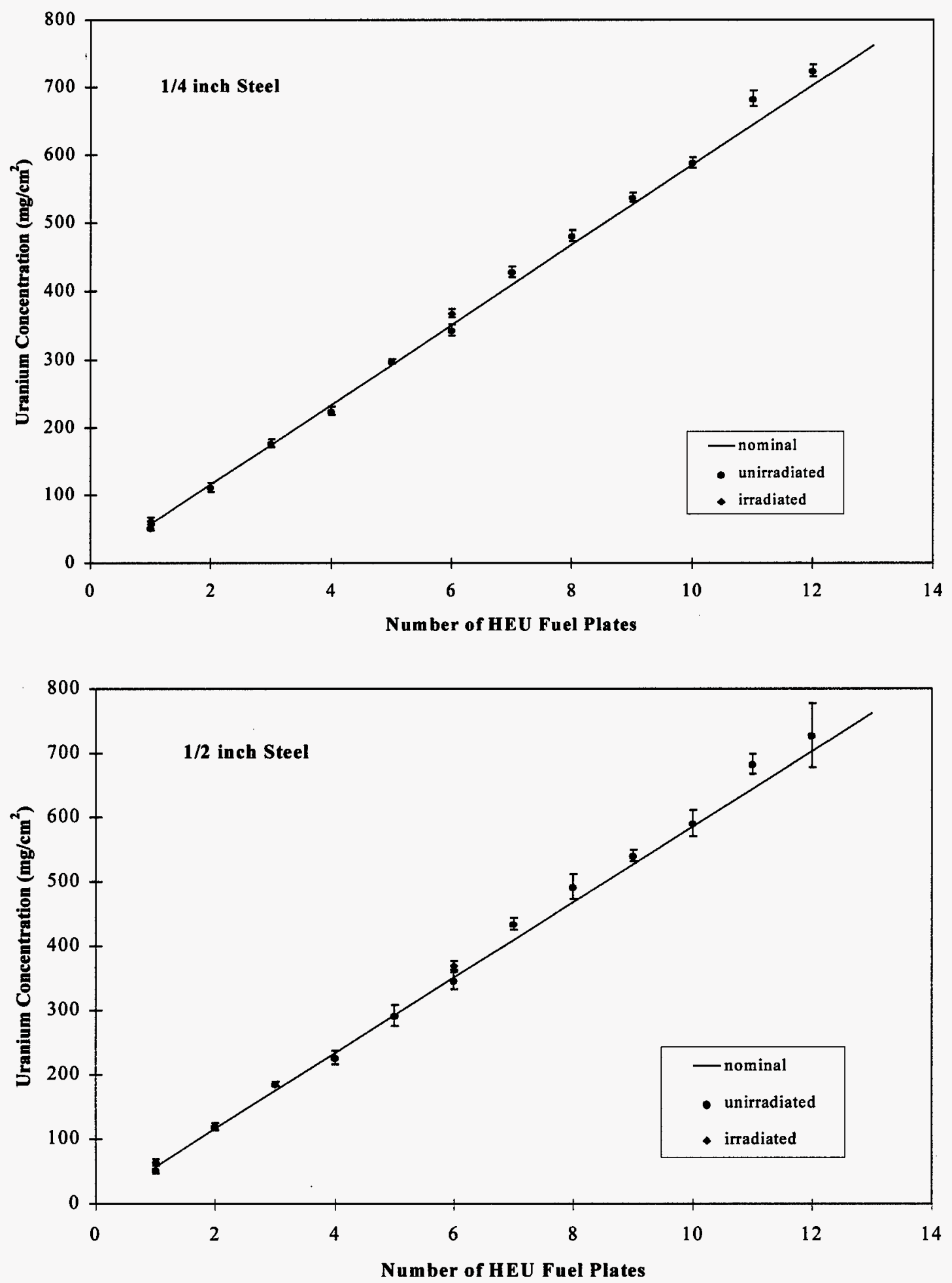

Figure 12. K-edge measurement of uranium concentration as a function of the number of HEU fuel plates in a stack. The solid line indicates the expected concentration based on the manufacturer's specifications. 


\section{Summary and Conclusions}

We have demonstrated that K-edge densitometry is a fast, accurate characterization technique for determining the total amount of uranium present in nuclear fuel plate assemblies. Accurate measurements of uranium concentration ranging from $60 \mathrm{mg} / \mathrm{cm}^{2}$ to $3000 \mathrm{mg} / \mathrm{cm}^{2}$ were obtained within a few minutes inspection time. The results were shown to be insensitive to a variety of matrix conditions, and operation of the system in a high radiation field was demonstrated.

The application of $\mathrm{K}$-edge densitometry to characterization of spent nuclear fuel at INEEL or Savannah River would require integration of the K-edge results with NDA measurements. The real-time $X$-ray image could provide a good indication of the geometry and condition of the fuel assembly. K-edge measurements made at selected points would yield the total uranium content, which, when combined with the geometric information and NDA measurements, could be used to improve the accuracy of the measurements of enrichment and burnup.

It was suggested by Canada et al.[9] in 1977 that K-edge densitometry could be used to determine the number of fuel plates in a MTR assembly. Given the improvements in technology over the past two decades, we feel that it is timely to reconsider K-edge densitometry as a useful aid in characterization of spent nuclear fuel.

\section{Acknowledgments}

We would like to thank Scott Wendt and the rest of the staff at the Iowa State University Nuclear Engineering Lab for providing their services and the facilities for carrying out these measurements. This work has been supported under the DOE Characterization, Monitoring and Sensor Technology Crosscutting Program. The activities reported in this manuscript were funded by the Department of Energy under contract No. W-7405-ENG-82 with the U.S. Government, through the Environmental Technology Development Program at Ames Laboratory.

\section{References}

1. C.L. Bendixsen, personal communication.

2. Allen Brewer and Trent Andes, personal communications.

3. T. Jensen, T. Aljundi, C. Whitmore, H. Zhong, and J.N. Gray, "Field Demonstration of a Portable, X-Ray, K-Edge Heavy-Metal Detector", Ames Laboratory internal report IS-5131 (March 31, 1997).

4. T. Aljundi, J.N. Gray, T. Jensen, C. Whitmore, and D. Robinson, "Development of a Portable X-ray, K-edge Heavy Metal Detector", Annual report for project CH-153001, September 30, 1995.

5. Taher Aljundi, Terrence Jensen, Doug Robinson, and Joseph Gray, "Development of an Xray K-Edge Heavy Metal Detector", International Tropical Meeting on Nuclear and Hazardous Waste Management, Spectrum '96, Vol. 1, p. 418-424. Published by the American Nuclear Society, Inc. La Grange Park, Illinois 60526 USA. 
6. Taher Aljundi, Terrence Jensen, Doug Robinson, and Joseph Gray, "Heavy metal contamination detection using X-rays", Review of Progress in Quantitative Nondestructive Evaluation, Vol. 15A, p. 465, Edited by D.O. Thompson and D.E. Chimenti. Plenum Press, New York, N.Y. 1996.

7. Doug Reilly, Norbert Ensslin, Hastings Smith, Jr., and Sarah Kreiner, Passive Nondestructive Assay of Nuclear Materials, NUREG/CR-5550, US Nuclear Regulatory Commission, Washington, DC (1991).

8. H. Ottmar and H. Eberle, "The Hybrid K-Edge / K-XRF Densitometer: Principles - Design Performance", Kernforschungszentrum Karlsruhe report KFK 4590, PWA 01/91 (1991).

9. T. R. Canada, D. G. Langner, and J. W. Tape, "Nuclear Safeguards Applications of EnergyDispersive Absorption Edge Densitometry", Nuclear Safeguards Analysis: Nondestructive and Analytical Chemical Techniques, Edited by E. A. Hakkila, American Chemical Society, Washington, D.C. (1978). 
Report Number (14)IS- $=5129$

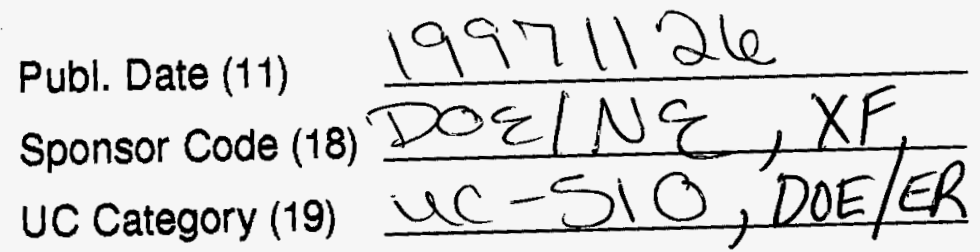

